\title{
Drugs and PAINs: A DrugBank analysis of pan-assay interference compounds
}

\section{Ion George Nicolae Daniel, George Mihai Nitulescu}

Carol Davila University of Medicine and Pharmacy, Faculty of Pharmacy, Bucharest, Romania

\section{Background:}

Many successful drugs have been developed in the pharmaceutical industry starting from hits discovered by Highthroughput Screening (HTS) methods, through various types of assays testing thousands of compounds against targets of interest in the therapeutic field. Unfortunately, several chemical motifs have been found to confer non-specificity against different targets, rendering compounds with such substructures to determine false-positive results in screening assays. These structures, widely known as PAINS (Pan-assay interference compounds), are often avoided by medicinal chemists when selecting hits from HTS assays, for toxicity- and potency-related reasons (Baell \& Holloway, 2010). However, several drugs classifiable as PAINS have already been approved, with many more being present in the drug development stages.

\section{Results:}

From 10631 compounds extracted from DrugBank, 198 substances were identified as being PAINS. 12 types of problematic substructures have been identified in DrugBank, the most common structures to be found as PAINs being substances containing catechols, quinones, rhodanine-related groups, hydrazones and phenolic Mannich bases.

Table 1 - Descriptives of PAINs extracted from

DrugBank - multiple categories possible

\begin{tabular}{|cc|}
\hline Compound status & Number of PAINs \\
\hline Approved & 38 \\
Investigational & 61 \\
Experimental & 123 \\
Withdrawn & 3 \\
\hline
\end{tabular}

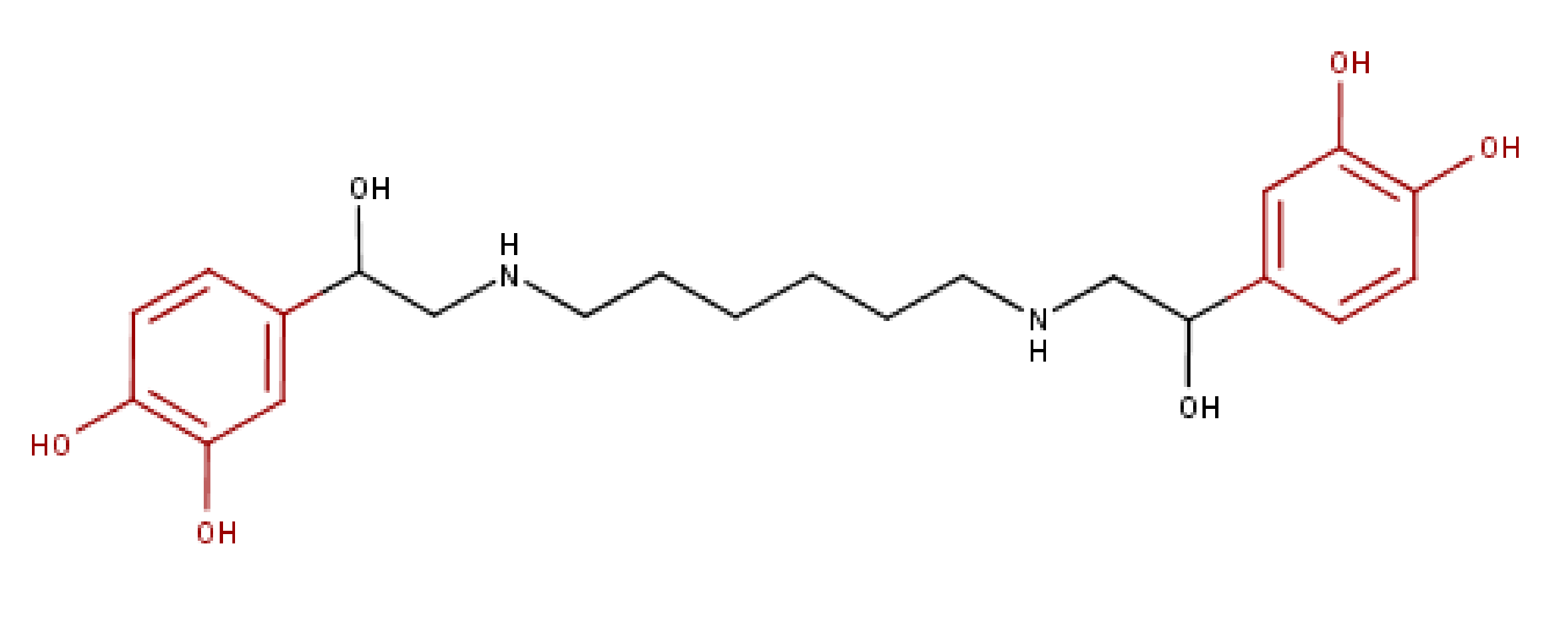

Hexoprenaline

\section{Objectives:}

The present work aims to investigate the frequency of use and utility of PAINs among the currently approved or indevelopment drugs by analyzing different types of PAINs comprised in the DrugBank chemical database, in order to better understand the impact of a pan-assay interference.

\section{Methods and materials:}

DrugBank version 5.0, containing 10631 structures, has been analyzed using OSIRIS DataWarrior 4.4.4 software, filtering for PAIN substructures indicated by Baell \& Holloway. Selected compounds representing PAINs set were managed and analyzed using DataWarrior, Microsoft Excel and SPSS Statistics, regarding approval status, pharmacology, targets,etc.

Table 2 - Types of PAINs structures identified in DrugBank database

\begin{tabular}{|c|c|c|c|c|c|c|c|c|}
\hline PAIN type & Structure & Count & PAIN type & Structure & Count & PAIN type & Structure & Count \\
\hline Rhodanine & & 3 & $\begin{array}{l}\text { 4-Hydroxy- } \\
\text { phenyl- } \\
\text { hydrazone }\end{array}$ & & 15 & $\begin{array}{l}\text { 2-Amino-3- } \\
\text { carbonyl- } \\
\text { thiophenes_A }\end{array}$ & & 1 \\
\hline $\begin{array}{l}\text { Rhodanine- } \\
\text { related }\end{array}$ & & 14 & Ene_five_het_G & & 12 & $\begin{array}{l}\text { 2-Amino-3- } \\
\text { carbonyl- } \\
\text { thiophenes_B }\end{array}$ & & 4 \\
\hline $\begin{array}{c}\text { Phenolic } \\
\text { Mannich bases }\end{array}$ & & 16 & $\begin{array}{l}\text { 1-Aryl-2,5- } \\
\text { alkylpyrrole }\end{array}$ & & 2 & Catechols & & 95 \\
\hline $\begin{array}{l}\text { 2-Hydroxy- } \\
\text { phenyl- } \\
\text { hydrazone }\end{array}$ & & 18 & $\begin{array}{l}\text { 2-Aryl-1,5- } \\
\text { alkylpyrrole }\end{array}$ & & 6 & Quinones & & 28 \\
\hline
\end{tabular}

Conclusion:

Although selectivity of a compound labeled as a PAIN is indeed deficient, these problematic compounds seem not to be as problematic as originally predicted in terms of toxicity and pharmacological profile, as numerous substances found to be PAINs are successfully used in current therapy. 